\title{
Discussing reproductive health in spinal care, part II: fertility issues
}

\author{
N. S. Korse ${ }^{1}$ - M. P. J. Nicolai ${ }^{2}$ S. Both ${ }^{3}$ C. L. A. Vleggeert-Lankamp ${ }^{1}$ \\ H. W. Elzevier ${ }^{2}$
}

Received: 11 January 2016/Revised: 26 February 2016/ Accepted: 26 February 2016/Published online: 1 April 2016

(C) The Author(s) 2016. This article is published with open access at Springerlink.com

\begin{abstract}
Purpose Due to advancing insights, discussing fertility in spinal care is an emerging topic. Studies among neurosurgeons to evaluate clinical practice about discussing fertility are non-existent. The aim of this study is to review knowledge, attitude and practice patterns regarding discussing fertility in spinal care.

Methods Dutch neurosurgeons and residents were sent a mail-based questionnaire addressing attitude, knowledge and practice patterns regarding discussing fertility.

Results Response rate was $62 \%$ (compared to mean of $28 \%$ in similar surveys) with 89 questionnaires suitable for analysis. Mean age was 42 years with $83 \%$ of respondents being male. A quarter of respondents stated neurosurgeons are responsible to discuss fertility, with $12 \%$ indicating to actually do this. Fertility is discussed more often with patients with cauda equina syndrome $(70 \%)$ and with men $(p=0.006)$. Merely $8 \%$ of respondents stated to have adequate knowledge on fertility preservation (FP); this percentage was higher for doctors with spinal surgery as specialty $(p=0.015)$. In case of cauda equina syndrome, doctors with more knowledge discussed fertility more often ( $p=0.002)$. Fifty-three percent of neurosurgeons wished to enhance their knowledge, in order to feel more comfortable to discuss fertility with their patients.
\end{abstract}

N. S. Korse

ninakorse@gmail.com; n.s.korse@1umc.nl

1 Department of Neurosurgery, Leiden University Medical Center, Albinusdreef 2, 2300 RC Leiden, The Netherlands

2 Department of Urology, Leiden University Medical Center, Leiden, The Netherlands

3 Department of Psychosomatic Gynaecology and Sexuology, Leiden University Medical Center, Leiden, The Netherlands
Five percent indicated to have ever referred a patient to a fertility specialist.

Conclusion With the exception of cauda equina syndrome, fertility is not routinely discussed in spinal care. Fertility is discussed more often with men. Recent guidelines state that discussing fertility is an essential part of good practice in spinal care. Education on fertility and FP needs to be integrated in the neurosurgical training program to create more awareness, and to enable clinicians to provide adequate information and care to the patient.

Keywords Spinal care $\cdot$ Fertility $\cdot$ Reproductive health · Practice patterns $\cdot$ Education

\section{Introduction}

Reproductive health is considered by the WHO to be one of the basic human rights, stating "it is the choice of each individual and couple, (...) to determine if they intend pregnancy, and if so, (...) the timing" [1]. Many diseases jeopardize reproductive health and as a result, fertility issues arise in several medical fields. Oncology care has been among the first to urge the need for discussing fertility, initially by running surveys among doctors and patients to expose the lack of discussion about fertility $[2,3]$, later by developing guidelines regarding the options for fertility preservation (FP) and the initiation of this topic in clinical practice, leading to a new field of "oncofertility" [4-8]. In spinal care, patients are faced with potential hazards to fertility and reproduction as well [9]. For example, $44 \%$ of all patients with cauda equina syndrome experiences sexual dysfunction (defined as any problem resulting in abnormal intercourse, ranging from, e.g., decreased penile or vaginal sensation to impotence or retrograde ejaculation), displaying 
that this group is potentially at high risk for in- or sub-fertility [10]. However, discussing reproductive health is far from first priority for spinal surgeons, which was shown in a recent survey among neurosurgeons, displaying only $26 \%$ of neurosurgeons discuss sexual health with their patients [11]. The first article in English literature acknowledging decreased fertility in spinal cord patients was written in 1948 and discussed male patients with spinal cord injury (SCI) [12]. Apart from the more obvious reasons for sub- or infertility in men with SCI (e.g., erectile and ejaculatory dysfunction), semen quality was found to be greatly reduced. Three causes were proposed: lifestyle factors [e.g., elevated scrotal temperature, infrequency of ejaculation, recurrent urinary tract infections (UTI)], physiological factors secondary to SCI (e.g., hormonal environment) and alterations in seminal plasma [13, 14]. Currently, the latter is considered to be one of the main causes [15]. This is compatible with the findings of reduced sperm motility in the ejaculate of SCI men (and adequate number and morphology) versus normal sperm motility in their epididymis [14]. Several treatment options for men were introduced, including in vitro and in utero fertilization after ejaculation through vibratory stimulation or electro ejaculation [16]. Due to several case reports about quickly deteriorating semen quality after SCI, cryopreservation of sperm as soon as possible after injury was proposed by several authors [17-19].

The focus on the male patient is striking when browsing through literature on SCI and fertility. Data on female fertility and SCI is scarce. Women with SCI however, do experience prolonged amenorrhoea after injury, which can take up to 9 months $[20,21]$. To complicate matters, during this anovulatory phase, unpredictable ovulation might occur, which makes it even more important to properly consult patients on fertility, and contraception [20]. When menses has returned, fertility of SCI women is assumed to be similar to the general population. However, virtually no data on fertility rates in SCI women are available [22]. With regard to pregnancy and labour, several health risks are identified for SCI women [23, 24]. In a large study of 472 SCI women of which $14 \%$ got pregnant after injury, complications like miscarriage, diabetes of pregnancy, prematurity and low birth weight (corrected for prematurity) were significantly more frequent after injury than before injury ( $75 \%$ versus $50 \%$ ). In addition, women with SCI displayed higher rates of delivery by caesarian section (18 versus $8 \%$ ) [25]. Apart from consequences of the disease itself, surgical treatments might impose an additional risk on fertility, in particular for men. Anterior spinal surgery, especially the transperitoneal approach, may cause damage to the hypogastric plexus and therefore cause retrograde ejaculation [9]. In women, damage to the hypogastric plexus has the potential to reduce pain sensations of the uterus and seems not to affect fertility in that sense. One retrospective telephone study in 2007 showed no decreased fertility among women after anterior spinal surgery [26]. However, literature on fertility after spinal surgery in women is sparse and might therefore not be representative.

An important risk for deteriorating medullary cord function, and thereby possibly affecting fertility, is surgery on the spine for tumor, trauma or degenerative disease. In particular in those interventions in which the surgery is done because the medullary tract is already at risk by the disease, the chance to further damage the cord, is considerable.

In 2010, a guideline was released by the Consortium for Spinal Care Medicine stating that (options of) fertility should be discussed with all SCI patients [27]. In the same period, instruments on how to measure infertility in SCI patients were proposed [28]. Discussing fertility is now adapted as one of the essential elements of primary spinal care [29]. Despite the fact that the attention for reproductive health and fertility issues in spinal care patients is increasing, data about practice patterns for discussing fertility in spinal care is nonexistent.

This study was designed to explore knowledge, attitude and practice patterns of neurosurgeons about discussing fertility with spinal care patients.

\section{Materials and methods}

\section{Participants}

In March 2013, all members of the Dutch association of Neurosurgery, which comprises both neurosurgeons and residents in neurosurgery (total 161) were invited to fill in a questionnaire. The questionnaire was developed by the authors of this article, based on the questionnaire used by Nicolai et al. [30], adapted for this purpose. A pilot study was performed in January 2013 among residents and neurosurgeons of the Neurosurgery department of the Leiden University Medical Center. According to feedback and comments, the questionnaire was further adjusted which leaded to a finalized version which was used for this survey (the questionnaire is available upon request). The questionnaire included 34 questions and was divided into the topics: sexual dysfunction and fertility issues. The results of the items on sexual dysfunction are discussed in a previous article [11].

\section{Items that were analyzed in this article}

1. Demographic data of respondent;

2. Level of knowledge on fertility issues and their treatment; 
3. Frequency of discussing fertility issues with patients;

4. Responsibility of the neurosurgeon to discuss fertility issues;

5. Knowledge about (possibilities to) referring patients with fertility issues problems.

Various questions were asked repetitively for different groups of patients (sex and age categories) to facilitate analysis regarding patients' sex and age. Questions were all stated referring to patients with general spine problems, unless specified otherwise. Questionnaires were accompanied by an invitation letter explaining reasons for and content of the study and sent by regular mail. A monetary incentive (opportunity to win book voucher) was used to motivate participants to reply. In case a participant did not reply, reminders were sent 1 and 2 months after initial invitation.

\section{Statistical analyses}

Data were analyzed using SPSS Statistics 23.0 (SPSS Inc., Chicago, IL, USA). Internal consistency of the survey was analyzed using Cronbach's coefficient $\alpha$. Means of numerical demographic values and answers to questions were analyzed with frequencies. Associations between categorical demographic data and numerical variables without Gaussian distribution were tested with the MannWhitney $U$ test; for paired data (either numerical without Gaussian distribution or ordinal), Wilcoxon signed rank test was used. Associations between ordinal or categorical independent variables and ordinal data were calculated with Mantel-Haenszel linear-by-linear association Chi squared test (comparable to Armitage's trend); Pearson Chi square test was used for categorical data. Comparison of paired ordinal data was done using Friedman's test, with Wilcoxon signed rank test and Bonferroni adjustment as post hoc test. For associations between ordinal variables and numerical data, not displaying Gaussian distribution, Kruskal-Wallis $H$ test was performed, with Mann-Whitney $U$ test and Bonferroni adjustment as post hoc test; for numerical demographics and numerical data without Gaussian distribution, Spearman correlation was used. Two-sided $p$ values $<0.05$ were considered statistically significant. Some questions with open, numerical and ordinal answers were grouped together for analysis.

\section{Results}

\section{Reliability of the questionnaire}

Items regarding the frequency participants ask about fertility displayed an acceptable internal consistency $(\alpha=0.70)$.

\section{Participants}

Of the 161 eligible participants, 99 returned the questionnaire, either after first invitation $(n=55)$ or after second ( $n=26)$ or third $(n=18)$ invitation, resulting in a total response rate of $61.5 \%$. Nine participants returned the questionnaire empty; reasons not to participate were lack of experience $(n=3)$, lack of interest $(n=2)$, lack of time $(n=1)$, working with a specific patient group not suitable for this study $(n=2)$ or no reason indicated $(n=1)$. One participant returned an almost empty questionnaire with too little information available for analysis.

This resulted in a total of 89 questionnaires that were suitable for analysis.

Of the participants, $83.1 \%$ were male, in accordance with the circa $90 \%$ male predominance in the Netherlands neurosurgical society. Mean age was 42.4 years (SD 9.6), with $71.6 \%$ of respondents being a neurosurgeon versus $28.4 \%$ being a resident. Mean experience in neurosurgical care was 9 years. Among the respondents, $42.5 \%$ had spinal surgery as his or her specialty. Characteristics of the responders are summarized in Table 1. Male respondents

Table 1 Characteristics of participants $(n=89)$

\begin{tabular}{|c|c|}
\hline & $n(\%)$ \\
\hline \multicolumn{2}{|l|}{ Sex } \\
\hline Male & $74(83.1)$ \\
\hline Female & $15(16.9)$ \\
\hline Mean age & $\begin{array}{l}42.4 \text { years (SD 9.6; range } \\
28-64 \text { years) }\end{array}$ \\
\hline \multicolumn{2}{|l|}{ Function } \\
\hline Neurosurgeon & $63(71.6)$ \\
\hline Resident & $25(28.4)$ \\
\hline \multicolumn{2}{|l|}{ Place of practice } \\
\hline University hospital & $40(45.5)$ \\
\hline Teaching hospital & $15(17.0)$ \\
\hline District general hospital & $3(3.4)$ \\
\hline $\begin{array}{l}\text { University }+ \text { district general } \\
\text { hospital }\end{array}$ & $23(26.1)$ \\
\hline University + teaching hospital & $6(6.8)$ \\
\hline $\begin{array}{l}\text { University }+ \text { district } \\
\text { general }+ \text { teaching }\end{array}$ & $1(1.1)$ \\
\hline \multicolumn{2}{|l|}{ Experience in neurosurgical practice } \\
\hline$<3$ years & $3(3.4)$ \\
\hline $3-5$ years & $11(12.4)$ \\
\hline $6-10$ years & $25(28.1)$ \\
\hline $11-15$ years & $15(16.9)$ \\
\hline$>15$ years & $35(39.3)$ \\
\hline \multicolumn{2}{|l|}{ Spinal surgery as specialty } \\
\hline Affirmative & $37(42.5)$ \\
\hline Negative & $50(57.5)$ \\
\hline
\end{tabular}

$N B n$ differs because some questions were skipped 
were significantly older than their female counterparts [mean age 43.6 (SD 9.43) versus 36.3 (SD 8.35); $p=0.006]$.

\section{Discussing fertility issues and sex of patient}

To the question "How often do you discuss the impact of disease on fertility with patients with general spine problems?" $87.5 \%$ of respondents answers '(almost) never' and $3.4 \%$ '(almost) always'. When asked about cauda

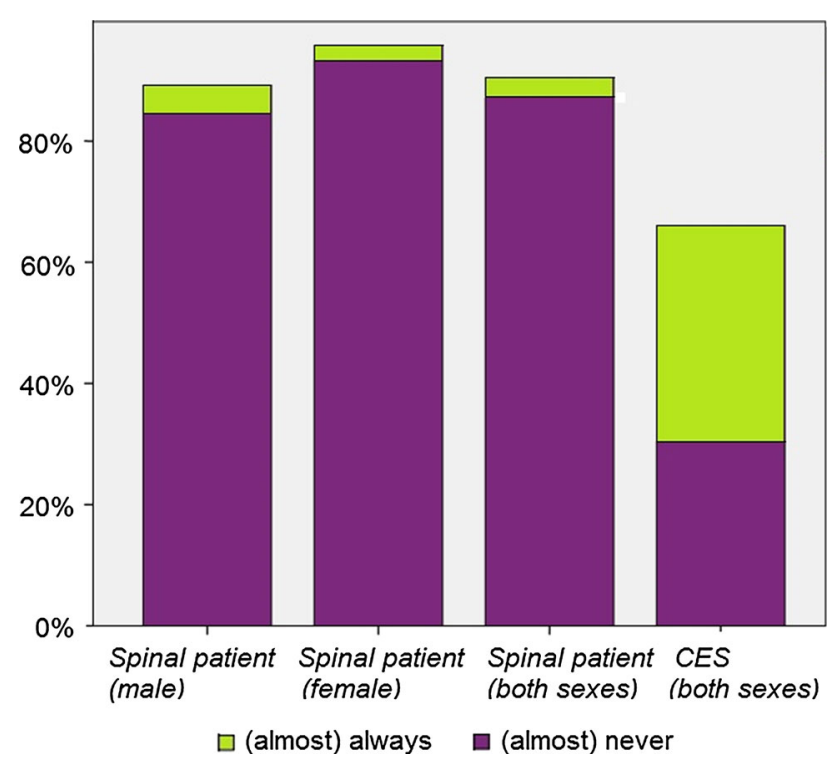

Fig. 1 Frequency of discussing fertility by neurosurgeons

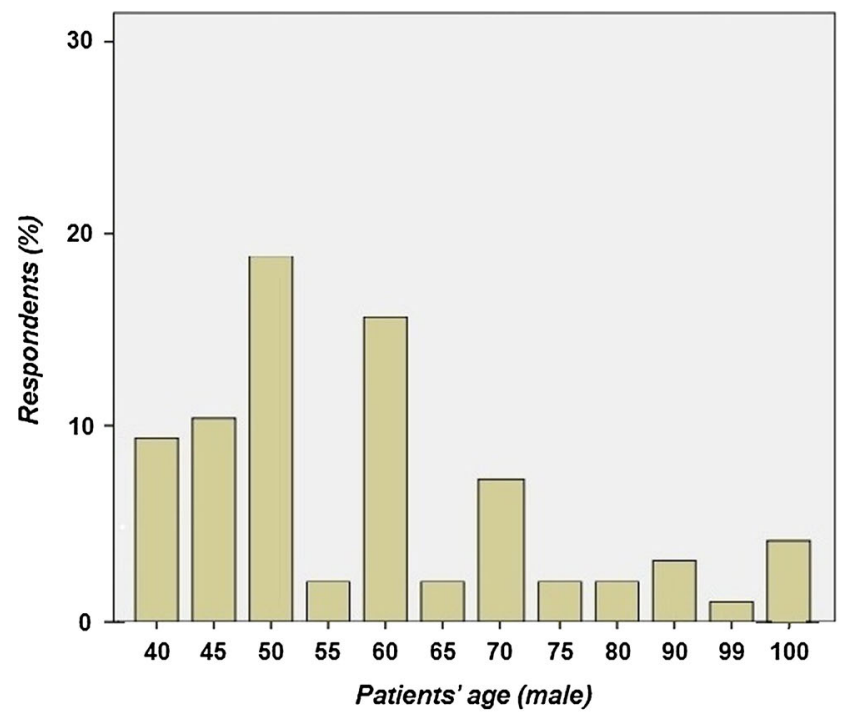

equina syndrome, $30.3 \%$ states to '(almost) never' discuss fertility issues while $34.8 \%$ says to '(almost) always' do that (see Fig. 1). Other possible answers were: 'in less than half of the cases', 'in half of the cases' and 'in more than half of the cases'.

Fertility issues are discussed less often with female patients than with male patients: $93.2 \%$ of doctors replies to (almost) never discuss fertility with their female patients, versus $84.3 \%$ for male patients. This difference is significant $(p=0.006)$. In addition, doctors discuss fertility issues up to a higher age with their male patients than with their female patients, see Fig. 2 [mean 56.7 years (SD 19.8) versus 47.3 years (SD 13.7), respectively; $p<0.001]$. Male doctors discuss fertility issues with their female patients up to a higher age than do their female counterparts (40.4 years versus 35.1, respectively). However, this difference is not significant $(p=0.43)$. The frequency of asking about fertility issues is not significantly associated with gender, age or any other demographic of the respondents.

\section{Responsibility}

According to $21.6 \%$ of respondents, the neurosurgeon has the responsibility to discuss fertility issues with patients between 16 and 44 years with general spine problems; $42.0 \%$ does not know who is responsible. Respondents who believe that the neurosurgeon is responsible, ask significantly more often about fertility $(p=0.031)$. Feelings of responsibility are not significantly associated with demographics of doctor.

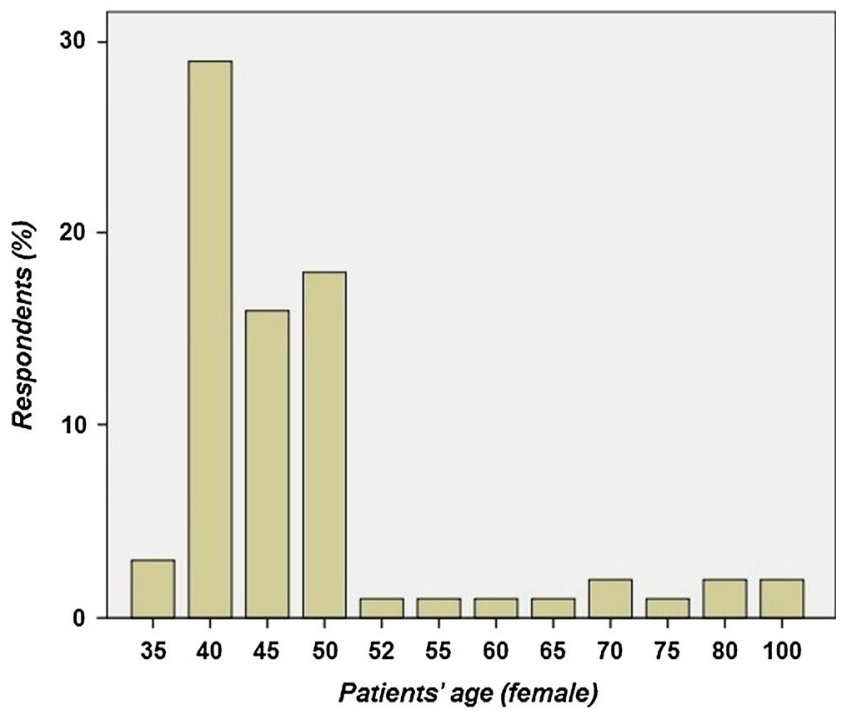

NB: Respondents who replied 'no idea' were omitted.

Fig. 2 Maximum patients age to discuss fertility according to neurosurgeons 


\section{Knowledge}

Regarding knowledge on FP options in patients with spinal diseases, $69.3 \%$ states to have (almost) no knowledge about this topic, $22.7 \%$ says to have 'some' knowledge and the remaining $8 \%$ indicates to have adequate knowledge.

More knowledge is significantly associated with spinal surgery as specialty $(p=0.015)$. More knowledge is not significantly associated with more frequent discussion about fertility, apart for patients with cauda equina syndrome, in which neurosurgeons who feel more confident about their knowledge, discuss fertility issues more often $(p=0.002)$. No association between present knowledge and feelings of responsibility is found.

Doctors who indicate they have more knowledge, discuss fertility up to a higher patients age. This correlation is significant for female patients, but just not for male patients ( $p=0.046$ versus $p=0.057$, respectively).

The majority of respondents $(52.9 \%)$ indicates that they prefer to enhance their knowledge on (discussing) fertility issues; female respondents answer significantly more often affirmative to this question (80.0 versus $47.2 \%$; $p=0.021$ ), similar to doctors below 34 years (84.2 versus $44.8 \% ; p=0.024)$, residents as opposed to specialists (80.0 versus $42.6 \% ; p=0.002)$ and those working in neurosurgical care less than 6 years (78.6 versus $47.9 \%$; $p=0.035$ ). Doctors who classify their current knowledge as adequate, have significantly less motivation to enhance their knowledge (56.8 versus $0 \%$, respectively; $p=0.026$ ).

Neurosurgeons who feel responsible to discuss fertility issues are significantly more eager to enhance their knowledge $(p<0.0001)$.

\section{Referrals}

When it comes to referring a patient to a fertility specialist, $95.5 \%$ state to '(almost) never' do that; the remaining doctors indicate to do that in less than half of the cases. Neurosurgeons who ask about fertility issues refer their patients significantly more often $(p<0.0001)$.

\section{Discussion}

Fertility issues are not commonly discussed in spinal care: $88 \%$ of respondents (almost) never consults his or her patient on this topic. Cauda equina syndrome is an exception in which $70 \%$ of neurosurgeons discuss fertility issues. A quarter of responding neurosurgeons stated that they believe that they have the responsibility to discuss fertility issues with spinal care patients. Discussion is initiated significantly more often in male than in female patients, regardless of doctors' sex or age. This study confirms that counseling on fertility leads to more referrals to fertility specialists. Merely $4.5 \%$ of the responding neurosurgeons has ever referred a patient to a fertility specialist.

This is the first study focussing on the knowledge, attitude and practice patterns of neurosurgeons regarding discussing fertility. Twelve percent of neurosurgeons discuss fertility with their patients; a fairly low percentage when compared to figures from oncology care surveys (60-95\%). We hypothesized that a reason for this difference is the fact that oncofertility is a longer standing field and therefore oncologists are more aware of the importance of discussing fertility in their patient population. The earlier introduction of aforementioned oncology guidelines seems to play an essential part in this. Oncology care surveys show a slight increase of discussing fertility from $60 \%$ before implementation of the guidelines $[2,4,5]$, to $67-95 \%$ afterwards $[31,32]$. Since this study is performed after introduction of the Consortium guideline, one can merely guess what the results would have been before implementation.

In order to attain a high response rate, this questionnaire was kept as compact as possible. This, together with other proven effective strategies to increase response rate, such as a monetary incentive and using mail-based questionnaires instead of web-based ones [33, 34], yielded a response rate of $62 \%$. This is extremely high compared to similar surveys with response rates ranging from 15 to $37 \%$ (mean $28 \%$ ) [31, 32, 35-38]. However, it is likely that clinicians who are not interested in the topic of this survey, have declined invitations more often. Therefore, actual rates of discussing fertility may even be lower among the general clinician population. An important remark in this context is that only $2 \%$ of neurosurgeons who returned the questionnaire indicated a lack of interest.

More than half of the responding neurosurgeons wishes to enhance their knowledge about FP. This percentage is lower than found among oncologists, of whom $87 \%$ wish to gain more info on FP [37]. Merely $8 \%$ of respondents are confident about their knowledge, as opposed to half of oncologists in a similar review [36].

Referrals to fertility specialists are rarely made $(4.5 \%)$; and, naturally, significantly more often by doctors discussing fertility with their patients. This contrasts sharply to figures from oncology surveys in which 47 to $82 \%$ refers to a fertility specialist. Oncology studies identified the following positive doctor predictors for referring: female sex, favorable attitude, gynecology or pediatrics as specialty, high frequency of discussing fertility and easy access to fertility specialist $[31,35,38]$. In the present survey, no positive predictors for referring, apart from high frequency of discussing fertility, were found.

Fertility is discussed more often with men than with women, and as well up to a higher age with male patients. 
The latter is easily explained by the restricted reproductive age of women compared to men. The fact that neurosurgeons discuss fertility more often with male patients is in concordance with the current focus of spinal literature on male fertility. However, like stated before, the hypothesis that fertility is not affected in SCI women is not supported by constructive research. The need for research on fertility in SCI women is essential, as was already urged by DeForge in 2005 [22]. Unfortunately, no new studies about this topic have emerged since.

Interestingly, doctors discuss fertility up to a higher age with female patients when they feel more confident about their own fertility knowledge (up to 55 years versus up to 36 years). This could be due to the fact that: (1) doctors with more knowledge, have this knowledge because they believe FP options should be easily accessible for everyone and thus also for women with more advanced age, or because (2) doctors with little knowledge, do not know that discussing reproductive health might still be useful for women with more advanced age (e.g., $>36$ years).

\section{Limitations}

The most important limitation of this study is that questions on barriers to discuss fertility were not included in the questionnaire. As mentioned before, this was done to obtain a compact questionnaire which greatly helped in attaining a high response rate.

In similar oncology surveys, oncologists mentioned barriers such as lack of knowledge, unawareness to whom to refer to, lack of time and too advanced illness of the patient [37-39]. Further studies regarding these barriers for specifically spinal care clinicians are indicated.

\section{Conclusion}

This study shows that fertility is not routinely discussed in spinal care, and that referrals to fertility specialists rarely take place. There is disagreement about the responsibility the neurosurgeon has in initiating discussion about fertility issues. According to current guidelines and consensus however, part of good practice includes discussing fertility issues in spinal care patients. Results of this study match our expectation that there is still a lot to improve in this area, especially when compared to oncology care. We propose integration of education on fertility in the neurosurgical training program to create more awareness and to enhance knowledge on FP options among neurosurgeons. As displayed in previous studies, creating referring facilities could positively influence the number of referrals. More education will enable neurosurgeons to provide adequate information and care to the patient. In a general light, more research regarding the barriers to initiate discussion about fertility in clinical practice and regarding fertility in women with spinal cord problems is needed.

\section{Compliance with ethical standards}

\section{Conflict of interest None.}

Open Access This article is distributed under the terms of the Creative Commons Attribution 4.0 International License (http://crea tivecommons.org/licenses/by/4.0/), which permits unrestricted use, distribution, and reproduction in any medium, provided you give appropriate credit to the original author(s) and the source, provide a link to the Creative Commons license, and indicate if changes were made.

\section{References}

1. WHO (2015). Sexual and reproductive health: About infertility. From: http://www.who.int/reproductivehealth/topics/infertility/ en/. Consulted on 8th January 2016

2. Schover LR, Brey K, Lichtin A et al (2002) Knowledge and experience regarding cancer, infertility and sperm banking in younger male survivors. J Clin Oncol 20(7):1880-1889

3. Schover LR, Brey K, Lichtin A et al (2002) Oncologists' attitudes and practices regarding banking sperm before cancer treatment. J Clin Oncol 20(7):1890-1897

4. Ethics Committee of the American Society for Reproductive Medicine (2005) Fertility preservation and reproduction in cancer patients. Fertil Steril 83(6):1622-1628

5. Lee SJ, Schover LR, Partridge AH et al (2006) American Society of Clinical Oncology recommendations on fertility preservation in cancer patients. J Clin Oncol 24(18):2917-2931

6. Woodruff TK (2007) The emergence of a new interdiscipline: oncofertility. Cancer Treat Res 138:3-11

7. Trost LW, Brannigan RE (2012) Oncofertility and the male cancer patient. Curr Treat Options Oncol 13(2):146-160

8. Noyes N, Melzer K, Druckenmiller S et al (2013) Experiences in fertility preservation: lessons learned to ensure that fertility and reproductive autonomy remain options for cancer survivors. J Assist Reprod Genet 30(10):1263-1270

9. Albright TH, Grabel Z, DePasse JM et al (2015) Sexual and reproductive function in spinal cord injury and spinal surgery patients. Orthopedic Rev 7(5842):74-79

10. Korse NS, Jacobs WC, Elzevier HW, Vleggeert-Lankamp CL (2013) Complaints of micturition, defecation and sexual function in cauda equina syndrome due to lumbar disk herniation: a systematic review. Eur Spine J 22(5):1019-1029

11. Korse NS, Nicolai MPJ, Both S, Vleggeert-Lankamp CLA, Elzevier HW (2016) Discussing sexual health in spinal care. Eur Spine J 25(3):766-773

12. Horne HW, Paull DP, Munro D (1948) Fertility studies in the human male with traumatic injuries of the spinal cord and cauda equine. N Engl J Med 239(25):959-961

13. Amelar RD, Dubin L (1982) Sexual function and fertility in paraplegic males. Urology 20(1):62-65

14. Brackett NL, Nash MS, Lynne CM (1996) Male fertility following spinal cord injury: facts and fiction. Phys Ther 76(11):1221-1231

15. Ibrahim E, Lynne CM, Brackett NL (2015) Male fertility following spinal cord injury: an update. Andrology (Epub ahead of print) 
16. Sonksen J, Biering-Sorenson F (1992) Fertility in men with spinal cord or cauda equina lesions. Semin Neurol 12(2):106-114

17. Sonksen J, Biering-Sorensen F (1994) Semen quality in the same man before and after spinal cord injury. case report. Paragplegia 32(2):117-119

18. Das S (2006) A case or rapid detoriation in sperm quality following spinal cord injury. Spinal Cord 44(1):56-58

19. Bechoua S, Berki-Morin Y, Michel F et al (2013) Outcomes with intracytoplasmic sperm injection of cryopreserved sperm from men with spinal cord injury. Basic Clin Androl 23:14

20. Berard EJJ (1989) The sexuality of spinal cord injured women: physiology and pathophysiology. A review. Paraplegia 27:99-112

21. Sauer PM, Harvey CJ (1993) Spinal cord injury and pregnancy. J Perinat Neonatal Nurs 7(1):22-34

22. DeForge D, Blackmer J, Garritty C et al (2005) Fertility following spinal cord injury: a systematic review. Spinal Cord 43(12):693-703

23. Bertosa H, Cellura M, Pierce L et al (1993) Women with spinal cord injuries require sensitive reproductive care. MCN Am J Matern Child Nurs 18(5):254-257

24. Jackson AB, Mott PK (2007) Reproductive health care for women with spina bifida. Sci World J 7:1875-1883

25. Jackson AB, Wadley V (1999) A multicenter study of women's self-reported reproductive health after spinal cord injury. Arch Phys Med Rehabil 90(11):1420-1428

26. Lavelle WF, Demers E, Fuchs A et al (2009) Pregnancy after anterior spinal surgery: fertility, cesarean-section rate, and the use of neuraxial anesthesia. Spine J 9:271-274

27. Consortium for Spinal Cord Medicine (2010) Sexuality and reproductive health in adult with spinal cord injury: a clinical practice guideline for health-care professionals. J Spinal Cord Med 33(3):281-336

28. Alexander MS, Brackett NL, Bodner D et al (2009) Measurement of sexual functioning after spinal cord injury: preferred instruments. J Spinal Cord Med 32(3):226-236
29. McColl MA, Aiken A, McColl A et al (2012) Primary care of people with spinal cord injury: scoping review. Can Fam Phys 58(11):1207-1216

30. Nicolai MP et al (2013) Discussing sexual function in the cardiology practice. Clin Res Cardiol 102(5):329-336

31. Forman EJ, Anders CK, Behera MA (2010) A nationwide survey of oncologists regarding treatment-related infertility and fertility preservation in female cancer patients. Fertil Steril 94(5):1652-1656

32. Louwe LA, Ter Kuile MM, Hilders CG et al (2013) Oncologists' practice and attitudes regarding fertility preservation in female cancer patients: a pilot study in the Netherlands. J Psychosom Obstet Gynaecol 34(3):129-132

33. Leece P et al (2004) Internet versus mailed questionnaires: a randomized comparison (2). J Med Internet Res 6(3):e30

34. Jb Van Geest, Johnson TP, Welch VL (2004) Methodologies for improving response rates in surveys of physicians: a systematic review. Eval Health Prof 30(4):303-321

35. Quinn GP, Vadaparampil ST, Lee JH et al (2009) Physician referral for fertility preservation in oncology patients: a national study of practice behaviors. J Clin Oncol 27(35):5952-5957

36. Duffy C, Allen SM, Dube C (2012) Oncologists' confidence in knowledge of fertility issues for young women with cancer. J Cancer Educ 27(2):369-376

37. Adams E, Hill E, Watson E (2013) Fertility preservation in cancer survivors: a national survey of oncologists current knowledge, practice and attitudes. Brit J Cancer 108:1602-1615

38. Loren AW (2015) Fertility issues in patients with hematologic malignancies. Hematol Am Soc Hematol Educ Program $1: 138-145$

39. Quinn GP, Vadaparampil ST, Bell-Ellison BA et al (2008) Patient-physician communication barriers regarding fertility preservation among newly diagnosed cancer patients. Soc Sci Med 66(3):784-789 